\title{
Analysis on Local Cultural Characteristics of Tibetan Folk Proverbs
}

\author{
Yan Chun \\ Sichuan University for Nationalities, Sichuan Province, Ganzi Prefecture, Kangding, 626001
}

Keywords: local cultural characteristics; Tibetan; folk proverbs

Abstract: Tibetan folk proverbs are rooted in the realities of production, life, customs, religious
beliefs, and national character in Tibetan areas. They have strong local flavors and become an
exotic flower in the treasure house of ethnic language arts.

\section{Introduction}

The Tibetan folk slang, commonly known as the "Dangbai” in the Tibetan language, is a literary form of Tibetan people's oral creation, embodying the essence of Tibetan folk language and the crystallization of wisdom. "It's hard to say, it's hard to take a handle." "The most delicious wine is nectar. The most pleasing words are slang." The slang has always been favored and liked by Tibetans. As long as they speak, they always use incisive and vivid proverbs. Explain the profound philosophy of life. In Tibetan areas, whether a person can skillfully use proverbs has actually become one of the criteria for measuring his eloquence and knowledge.

Literature is an objective reflection of the real world. Any form of literature is subject to the uniqueness of regional culture and is subject to the natural landscape and human customs of the region. Therefore, the localization of literary content has been realized in its subject matter and image. There is a strong local complex. [1] The same is true of folk slang that is circulated in Tibetan areas. Whether it is the proverb itself or the scene of activities, the humanistic care for Tibetans' production, life, customs and mindsets constitutes a rich folklore of folk slang.

\section{Tibetan Proverbs Vividly Reproduce the Rich Plateau Life}

Because local literature is deeply rooted in the real soil of local production and life, Tibetan folk proverbs will inevitably reflect the daily life of Tibetans. They often use Tibetans to get familiar with the familiar things in their lives and the unique production experience of Tibetans. Life experience to compile slang exudes fresh and rustic features.

Therefore, many images in Tibetan folk proverbs originate from the important position of Tibetans such as yak, sheep and horses. Livestock, such as "If you want more wealth, you will feed more cattle and sheep." "The cattle and sheep are the treasures of the herdsmen, and the six valleys are the treasures of the farmers." "The wolf can only eat weak calves and sheep, but when they see the yak, they are afraid of three points." [2] Tibetans have been dealing with animals such as horses, cattle and sheep all the year round. The prosperity of the six animals is their biggest concern. At the same time, we can also see how the herdsmen living on the grasslands cherish and love these animals, and even reveal their possession. The people have deep pride. In addition, with the migration of time, Tibetans gradually mastered the methods of grazing and the characteristics of livestock in production practice. There are also many proverbs about the livestock habits of livestock in the proverbs, such as "the road is not as good as the horse, the ice road the cow is stronger than the horse; the mountain scorpion is faster than the horse, and the downhill horse is stronger than the scorpion." "I want to drink milk tea for breakfast, and I have to go to the milk in the evening." "The downhill horse has to lean back and ride to the river. [3] These proverbs are the wisdom of Tibetans in the long-term animal husbandry life, a vivid portrayal of Tibetan nomadic life, full of rich plateau and local flavor. 


\section{Tibetan Proverbs Shows the Unique Tibetan Folk Culture}

The local customs and customs are also the areas in which folk slang is often expressed. The unique living environment and habits of Tibetan areas are reflected in the proverbs. For example, the proverb "gives the milk out of the ghee, stirs the water and foams." Although it is sweet, it is still chanting. "[4] The "bovine", "sheep", "ghee" mentioned in the above-mentioned proverbs are known as the "four treasures" of the Tibetan diet. The Tibetans living in the alpine region mainly rely on these foods to maintain the energy necessary for the body and these foods appear repeatedly in the Tibetan Mastiff, showing their importance in the production and life of the Tibetan people.

Tibetan areas also have a long tradition of wine culture and drinking customs, such as the proverb "Goat sees willow, Tibetans see wine." "Long-awaited guests have come, the old wine is old It is well-brewed."[5] It reflects the importance of wine in the daily life of Tibetans and Tibetans' preference for wine. The wine here mainly refers to the Qinglan wine, which is unique to Tibetan areas. Qinglan wine is for Tibetans. The symbol of joy, happiness and friendship is often used as a drink in the festive moments of family and friends gathering and welcoming guests. The boldness and enthusiasm of Tibetans can be seen in such moments and will infect people around them.

The etiquette customs formed by Tibetans in their long historical process are also abundantly found in proverbs. "There are layers in the tower, and people have children." "The father is present in the son of Moduo; the mother is alive, and the daughter is not authorized."[6] Tibetans pay great attention to etiquette in their daily lives, especially emphasizing the respect of their elders in their daily lives. Whether it is at a family's dinner table or in a grand ritual activity in a village, they are young and orderly, and have their own set of strictness. "The son did not have a child. Do not name it first.” [7] Before the Tibetan child was born, he could not name the child or knit clothes for the child. Tibetans thought this was an ominous sign and would hurt the child's strength. "Not seeing the Buddha does not take off his cap and not seeing the river not take off his boots."[8] The hat-trimming ceremony is a ceremonial custom in the Tibetan area, especially entering the Buddhist temple to worship the Buddha. Out of respect for the deity, one must be sincere and must take off the cap. "Lhasa is not a strange hometown. The temple is not warm in the bedroom." [9] The temple refers to the temple dedicated to the Buddha. In the Tibetan area, almost every house has a Buddhist temple in the house. A quasi-high-pitched chanting can not be used to draw a Buddha's finger. Usually, there is no room in the temple, especially women and couples. Only monks who are noble or famous can stay. The above few proverbs reflect the customs and etiquette of the Tibetan people, which gave us a preliminary understanding of the Tibetan etiquette and customs, and can deeply feel the rich cultural background reflected by the Tibetan proverbs.

\section{Tibetan Proverbs Reflect the Tibetan National Spirit and Value Orientation.}

The folkness of Tibetan folk idioms is also reflected in Tibetans' attitudes to life and national personalities. "In the process of compiling proverbs, people also compiled their own attitudes, tastes, and ideas. The simple optimism and humor of the Tibetan people are reflected in the proverbs."[9] Thus, this also makes Tibetans Folk slang is not only static text, but also instills the vitality of the Tibetan people.

In order to adapt to the harsh and harsh natural environment, Tibetans have identified the value of labor to create beauty in long-term production practices, so many proverbs reflect the hard-working qualities of Tibetans. Such as "talk to think about it, work hard to rush." "If you want to eat a good ghee, you must feed the cows first." "Carefully feeding cows, morning tea is oily." [10] From these proverbs, we You can feel the honest and optimistic attitude and life of the Tibetans. They are not afraid of hardships, work hard, and work diligently. They firmly believe that as long as you give up your work, you will certainly gain and your life will be even better.

Advocating unity is also an integral part of the Tibetan people's spiritual culture. Tibetans live in the snowy plateau where there are few people, traffic jams and environmental sinisters. Therefore, 
Tibetans recognize the importance of people and the importance of harmony, unity and mutual assistance. [11] In Tibetan proverbs, there are many proverbs about collective power cognition, such as "the chiefs can work together, the material wealth is rolling in; the parents and children can be united, and the family wealthy villages are prosperous." "As long as the rope is twisted, the wool is also can bundle the male lion." "The tiger does not dare to eat hordes of yaks." "Three people discuss, you can cover the temple."[12] It can be seen that Tibetans attach great importance to collective consciousness and national consciousness.

The Tibetan folk slang has a certain degree of integration of the brave and optimistic spirit of the Tibetans. "The four-footed yak will fall, not to mention the two-footed person." "When you graze, you don't sing folk songs, the wooden cows graze are not fragrant; when singing, there is no salt in the tea."[13] These proverbs show that Tibetans face harsh and dangerous natural environments and complex political environments. They also maintain an optimistic and persevering national character. Tibetans living on the plateau are with their strong and resolute, open-minded and optimistic, they have accumulated vicissitudes and wisdom in the long history, and lived harmoniously and superbly in the spiritual land. The proverb also reflects Tibetans' hospitality and sincere personality. When dealing with people, Tibetans pay special attention to honesty, keeping promises, and opposing Eli's intersection. "There are wines that everyone can drink, and there is something to say in person." "The rich people are savory and treat customers. It is true that the poor use tea to treat guests." "The broad-minded chest can accommodate hundreds of horses." [14]

\section{The Embodiment of Religious Thought in Tibetan Proverbs}

The Tibetan folk sayings also reflect the profound influence of Tibetan Buddhism on the Tibetan region's history and culture, language expression, and social life. The ethical concept of Buddhism has a far-reaching impact on the Tibetan society and is the cornerstone and important content of the traditional Tibetan social ethics. "Whether it is religious or non-religious, the Tibetan temperament naturally merges these Buddhist lessons because of the continuous development and cultivation of Tibetan Buddhism.”[15]

In the slang, we can see the influence of Buddhism on the daily life of Tibetans, such as "born in the arms of my grandmother and offering it to the lamas."[16] Reflecting the custom of the old days in Tibetan areas, the boy at home At least one must be converted to Buddhism. In Tibetan areas, some poor people still send their children to temple monks because of the hardships of life. Proverbs reveal the blood-soluble relationship between Tibetans and Buddhism. To a certain extent, it also reflects the mother's sadness and affection for her son. Influenced by Buddhist thoughts, in the past, the main criterion for evaluating a person's morality was to master the knowledge of Buddhism, such as "Want to use the materials to feed the horses, and to learn to learn the five Ming." "The mouth of the horse is not hard. We haven't learned five things but have a big breath."[17] The "Five Ming" here is a generalization of the system of Tibetan cultural knowledge. Tibetan intellectuals often refer to learned scholars as "learning to be rich for five years" and "five "Study" is divided into "Big Wuming" and "Xiaowuming". The former refers to poetry, rhythm, rhetoric, song and dance, and astronomical calculation. The latter refers to phonology, Orthodox, Buddhism, technology, medicine, and mastering Wumingzhi. Learning has become a standard for Tibetans to measure the level of knowledge of a person.

Tibetan Buddhism enjoys a lofty position in Tibetan social life. The Tibetans also maintain incomparable compliance with the Buddha itself. However, the huge monk system is mixed with fish and dragons. There are many believers who are indifferent to each other and do whatever they want. Buddhism is strict. The commandments became their powerful hypocrisy, and the generous offerings of the Tibetans' devotions became the main means of gathering their wealth. The Tibetans saw through the true intentions of this group of people and expounded their face through the proverbial language, satirizing some of the unworthy behaviors and degrading behaviors of defamation and hypocrisy. "Do not kill people" is said by the Buddha, but the lamas have to eat fat. "The wearer is not necessarily a lama, and the Buddha is not necessarily a good one." "Interpretation of Manjusri Bodhisattva, eyes must be on the other side of the horse." [18] These 
proverbs reflect to a certain degree the rationality of Tibetans Thinking and correct value judgment ability have a set of criteria for judging the merits and demerits in the hearts of Tibetans. Even if the Tibetans enjoy a high status of monks, as long as they are against morality, Tibetans are brave enough to criticize and testify.

"Language, as a form of cultural expression, is specifically represented by the fact that certain cultures often add a certain kind of branding to the language.”[19] Folk slang proverbs spread in Tibetan, depicting the Tibetan people's production and life, customs, beliefs, customs, etc. The symbolic imprint of a distinctive regional culture has provided us with lively paintings full of local flavor. On the other hand, it also provides a certain degree of historical value for the local economy, politics and culture. It is the realistic significance of the cultural interpretation of folk literature. Tibetan culture is extensive and profound. The efforts we have made are like picking up sea shells. There are many rich and splendid cultures that we need to further interpret.

\section{References}

[1] Gui Zhihao. On the Cultural Interpretation Value of Local Literature--Analysis of the Locality of Western Zhejiang Literature, Zhejiang Social Sciences No. 5, 2010, p. 100

[2][3][6][7][12[18]] Li Shuangjian, Quni. Tibetan Proverbs Collection [M]. Beijing: Central University for Nationalities Press, 1989.7.

[4][5][8][10][16] Jin Jinhua, Zhuang Jing, Ge Tsang Dunzhu. Tibetan Proverbs [M]. Chengdu: Sichuan People's Publishing House, 1980.

[11][13][14] [15][17]Song Xingfu. Tibetan Folk Proverbs [M]. Chengdu: Sichuan Publishing Group Bashu Book Society, 2004

[9] Li Xiaoli. Folk Factors in Tibetan Folk Literature and Folk Literature[J]. Qinghai Nationalities Research, 2001. (3).

[16] Dan Zhuang Ben. Buddhism and Tibetan Literature [M]. Beijing: Central University for Nationalities Press, 1988.

[19] Zhuang Kongji. General Theory of Anthropology [M]. Taiyuan: Shanxi Education Press, 2003:183. 